\title{
Food Security in the Middle East
}

\author{
Arwa Hamaideh \\ $\mathrm{PhD}$ Assistant Researcher Water and Environment Research and Study Center-University of Jordan, Amman \\ P.O Box 11942 \\ Email:Hamaideh.arwa@ju.edu.jo
}

\begin{abstract}
The Middle East region has been faced with various challenges that are associated with food security. These are perpetuated by water scarcity, an increase in the population numbers in the region, climate change and unemployment. Notably, these factors are intricate and self augmenting and thus, the problem is very complex. Most recently, the theory of virtual water has been proposed as the best approach of addressing this scenario.

However, this study found out that various social, cultural, economic and political factors undermine its implication. The present trends indicate that the region is highly dependent on food imports and that the trend is set to increase in future. Besides highlighting the various challenges that the region faces in a bit to attain food security, this study presents viable approaches like the population control and the increased education levels and awareness creation that can be used to address the challenges in a sustainable manner.
\end{abstract}

Keywords: Middle East, food security, virtual water, trends.

\section{Introduction}

Most challenges, that the population of the Middle East grapples with, emanate from weather related complexities. Of great reference in this regard is the food insecurity that threatens the very survival of the population. Essentially, about sixty percent of the region is considered to be hyper arid or arid. As such, food production in the region can not be entirely dependent on rain fed agriculture. Arguably, the region is considered to be experiencing the largest food deficit than any other region across the globe. This presumption is based on the increase in imports with regard to cereals for consumption. In this respect, the World Bank (2008) ascertains that apart from Syria, the remaining countries have consistently featured on the worlds greatest cereal importers chart since 2006. A comparative study carried out by Yemtsove (2008) indicated that in the year 2007, the amount of cereals imported by the region is equivalent to 2.9 billion cubic meters of water.

The increase in cereal imports is attributed to the rapid population growth being experienced in the region. Notably, the countries can be considered to have the fastest rates with regard to the population's growth. In addition, it is posited that the rising imports haves being experienced across the globe has also contributed to increased consumption of cereals in the region. This situation has further been compounded by the scarcity of water in the region. According to Naff (1995), this is the top most reason as to why food production and the overall food security in the region is at stake.

\section{Food Security: Present Trends}

Numerous studies, including Dyson (2006), indicate that the food security situation in the Middle East continues to face various challenges. In the recent past, the region has experienced an unprecedented rise in food prices. This is because of lack of water that makes agricultural production very costly. The food production is further compounded by the long term neglect of agricultural production by the government. Initially, the food importation was less costly and as such, governments could cheaply import food, subsidize the same and avail it to the population at affordable prices. However, this has long changed as global food prices have increased significantly. More than ever, governments are finding it expensive to import food and subsidize the same accordingly. This is even more difficult for countries like Jordan, Egypt and Palestine that have low levels of income (Dorosh, 2008). The implications of rising food prices have been far reaching. In particular, Dyson (2006) indicates that this has led to instability that as been manifested through riots in Egypt and Jordan. This has even made the population more vulnerable as extremist groups use the opportunity to win the confidence of the citizens by offering subsidized services. 
Table 1: Trends: Percentage of the population Faced with Food Insecurity

\begin{tabular}{|l|l|l|l|}
\hline Country & 2006 & 2007 & 2008 \\
\hline Yemen & $34 \%$ & $53 \%$ & $84 \%$ \\
\hline Egypt & $24 \%$ & $25 \%$ & $27 \%$ \\
\hline Lebanon & $15 \%$ & $27 \%$ & $31 \%$ \\
\hline Jordan & $14 \%$ & $25 \%$ & $29 \%$ \\
\hline West Bank and Gaza & $31 \%$ & $53 \%$ & $65 \%$ \\
\hline Ukraine & $11 \%$ & $8 \%$ & $7 \%$ \\
\hline Syria & $4 \%$ & $2 \%$ & $3 \%$ \\
\hline Palestine & $16 \%$ & $28 \%$ & $33 \%$ \\
\hline
\end{tabular}

FAO (2009)

\section{Indicators of Food Security}

Global surveys have previously employed vital indicators in their classification of countries as either being food secure or insecure. In particular, food aid and the proportion of cereals consumed domestically are the key indicators of foods security. The latter is usually derived from the imports of a country. In this respect, it is believed that countries that tend to import more grays are usually at a higher risk of food insecurity in instances where global reserves decrease. Relatively, national wealth is also an indicator that has been used to determine the status of food security across the globe. In this regard, FAO (2009) posits that a wealthy country has the capacity to cater for its food requirements in a sustainable manner. This is regardless of the fact that the domestic consumption may constitute a great percentage of imports. In addition, Mrabet (2006) argues that the wealthy countries are usually cushioned from the negative implications of food insecurity and are unlikely to have a shortage of grain supply. In most cases, they are able to survive even in cases were the prices soar as they can easily make higher bids when the markets become competitive.

\section{Food Aid}

In this respect, Benson, Minot, Pender and Robles (2008) ascertain that food aid is the most obvious indication of food insecurity in a give region. Fundamentally, it is believed that any country that opts for food aid has supply problems. Notably, six of the nine countries found in the Middle East have relied on food aid in 2008. Iran and Syria's pertaining to food aid have been considered to be insignificant at a national level because they were less than $0.15 \%$. However FAO (2008) considers Yemen and Lebanon to be middle -size recipients of aid. In particular, $2.4 \%$ and $2.9 \%$ of Lebanon's and Yemen's domestic food consumption was attributed to food aid respectively. Then, Jordan and Palestine are considered to be the biggest beneficiaries of food aid in the region. Since 2008, FAO (2009) indicates that food aid in Palestine has risen to constitute $32 \%$ of the total consumption. Seemingly, Jordan also received a significant $15 \%$ of food aid in 2008 .

\section{Cereal Imports}

In this regard, the countries are categorized in to three main classes: those whose imports make up less than $50 \%$ of the national cereal consumption, nations whose imports make up $51-84 \%$ of its domestic consumption and finally, those whose imports constitute $85 \%$ of the domestic consumption. Notably, the first group is comprised of only two countries, Syria and Iran. According to FAO (2009), imports in these countries constituted only $10 \%$ and 30\% respectively of the entire domestic consumption during 2008. Likewise, the second group constitutes two countries that include Yemen and Saudi Arabia. In particular, Saudi Arabia had 66\% of its domestic consumption being comprised of imports while Yemen had $75 \%$ of its cereal consumption comprising of cereals (FAO, 2009). The remaining six countries constituted the third category.

\section{Wealth levels}

With regard to the wealth levels, FAO (2009) argues that the wealth levels in the region differ considerably. In particular, it indicates that Kuwait, the UAE and Saudi Arabia and Israel have been cited to have per capita incomes that are above $\$ 10,000$. Then, Syria, Iran, Jordan and Lebanon are considered to have moderate incomes that range between $\$ 3000-7000$. Finally, the population in Palestine and Yemen is considered to be on the lower side with its income ranging between $\$ 730$ and $\$ 800$ respectively (FAO, 2009).

Based on the above indicators, it is important to acknowledge that food security amongst countries in the Middle East vary considerably. Notably, the UAE, Kuwait and Saudi Arabia exhibit a high degree of food security. This is regardless of their high dependence on imports. The stable food status can be attributed to their relatively high income levels that empower them to purchase all their food requirements. This is augmented by the stable global market. Further, recent trends indicate that despite the fact that Saudi Arabia has experienced an upsurge in its population, it has been able to reduce its dependence on food imports. In addition, Iran and Syria 
can also be considered food secure as they produce relatively high amounts of cereals than their counterparts. Lebanon is considered to have a low status with regard to food production because of it's over reliance on food aid. In addition, it also relies heavily on food imports. Seemingly, Palestine and Jordan can be considered to be food insecure. Palestinians in particular have the lowest income levels, are dependent on food aid and rely heavily on imports too.

\section{Imports Vs Exports in the Middle East}

There exists a sharp contrast between the imports and exports in this region. Essentially, Rutan (2002) contends that there has been a significant rise in imports as compared to the exports. In particular, wheat and other types of cereals have been identified to be the main types of food that are imported in the region. Statistical evidence indicates that in the period between 2008 and 2009, wheat constituted a significant $22 \%$ of the total imports. Barley on the other hand constituted $25 \%$ of the total imports in the region. In addition, it is indicated that the region is also a major importer of vegetable oil and other oil meals. In particular, this assumed close to $12 \%$ of the total imports between 2008 and 2009. Further, FAO (2009) indicates that these rates are expected to increase in future.

Notably, the increase in population growth and the diversification of the same has also led to diversification of diets and increasingly, more animal and dairy products are being consumed than in the past. In addition Gleick (2000) affirms that increased urbanization has also resulted in to the change in dietary patterns. The urban population is believed to prefer refined food, livestock and dairy products to grains and cereals.

An increase in imports in the region has been attributed to the increased demand for food and the decrease in the resources employed in the production of the same. Statistical evidence asserts that the imports have increased from $36.4 \%$ in 2000 to close to $44.2 \%$ in 2007 (WHO, 2008). This implies an estimated 3.5\% rise in the imports. They are led by cereals and feed grains, then followed by cotton, tobacco and finally dairy and livestock products. In his review, Cline (2007) indicates that the region also exports fruits, nuts, cereals, feed grains and vegetables. Currently exports constitute around $34 \%$ of the total production. These are mainly destined for the European Union countries, apart from a few vegetables and fruits.

The current state of food insecurity in the Middle East is further threatened by the implications of climate change. According to the report presented by the Food and Agriculture Organization (2009), climate change is likely to have more grave implications on food production in this region. These according to the report will hit the local farmers who entirely rely on rain fed agriculture the hardest. The four main facets of food security that are likely to be affected include food availability, accessibility, stability and utilization. As such, the population affected is expected to suffer from malnutrition and other nutritional related disorders. In particular, FAO (2008) indicates that the shifts in rainfall patterns are likely to avoid local production of vital staples like wheat and rice. This implies that here is a likelihood that the amount of food available to the population will decrease. Countries such as Yemen and Palestine have been particularly singled out to be at the highest risk because of the increase in population growth, low income levels and acute water shortages.

With regard to the food availability, climate change has had adverse implications on the fundamental elements employed in food production. The rural population is considered to be the most affected by various relative factors such as loss of livestock continued crop failure and reduced availability of natural resources from fisheries and forests. In addition, the change in weather patterns has culminated in an emergence of new and resistant pests and diseases that affect crops trees and animals. This has had direct negative effects on the quantity and quality of food and has led to a rise in food prices (WHO, 2008).

Further, the extreme weather conditions that are related to change in weather patterns has had various impacts on the assets and sources of livelihood of both the urban and rural populations. These have greatly threatened the supply of food in the region. In this regard FAO (2009) indicates that the countries in the Middle East are continuously struggling with prolonged droughts, increased intensity of rainfall and other implications associated with irregular weather patterns. Decrease in availability of food and water is likely to lead to sanitation problems and incidences of malnutrition. From the sociological standpoint, this would increase the incidence of conflicts and increase tensions between communities as they migrate to other regions in search of food (WHO, 2008). The concept of the 'newly hungry' has also been cited by World Bank (2008) to be a result of climate change. This is attributed to the decrease in food production and the subsequent increase in prices of the food. As a result, there exists a segment of the population that has sufficient financial resources but can not afford food because of the increased prices. This will lead to an increase in nutritional disorders.

\section{Addressing Virtual Water}

As indicated earlier, the water problem in the Middle East is really pronounced. The region has very few water resources that are available for production. Presently, it is indicated that $60-80 \%$ of the available water resources are employed in Agricultural production (Benson et al., 2008). It is certain that water is very elemental in environmental wellbeing and economic prosperity. However, the Middle East experiences a significant shortage 
of this vital commodity. Although FAO (2009) demonstrates that water shortage problems are being experienced on a global scale, it is notable that the Middle East is the worst hit by this predicament. In this respect, the region is considered to have a high percentage of arid land and receives very little rainfall. Likewise, the demand for water in the region is increasing notably because of the invariable increase in population growth. This has led to a strain in water resources that are already limited. Current statistics show that $16 \%$ of the population lacks safe drinking water. Further, they show that more than 80 million persons in the region lack proper sanitation (FAO, 2009).

Furthermore, certain countries in the region compromise the availability of water by over mining, irrespective of the fact that the water resources therein have already been over exploited. Shortages are further compounded by incidences of water pollution that are related to contamination by pesticides and fertilizers, huge deposits of solid wastes along river banks, dumping of industrial as well as municipal wastes in the rivers and other sources of water and uncontrolled and persistent seepage of wastes from and fill. In this regard, Dyson (2006) asserts that not only do these wastes contaminate the fresh water resources, but they also expose the already vulnerable population to health risks.

With the projected increase in population, the demand in water resources is set to increase significantly. Statistics indicate that if population growth continues unabated, the countries will have only enough water for domestic production by 2030 and none for Agricultural purposes (FAO, 2009). This condition is likely to make it difficult for the region to assure its population of food security. The best option in this regard lies in the importation of affordable virtual water. This takes the form of viable food staples and is instrumental in assuring the region of food security.

Employment of virtual water refers to the importation of the consumption foods that require significant quantities of water to produce (Naff, 1995). These often take the forms of staples and can be easily shipped and stored for long periods of time. They are sourced from countries that have plenty of water from natural sources as well as arable land for food production. These staples include food oil, dried grains, dried beans, fodder and frozen fish and meat products. They are then stored in silos, cold storage facilities and warehouses. Buchwald and Shuval (2000) indicate that this presents a more sustainable and cost effective method of ensuring a steady food supply for the population in the region. This can then enable the countries to engage in minimal agricultural production to cater for the vegetables and salad needs. Comparatively, this requires less water than domestic production of cereals.

In his review, Cline (2007) ascertains that usually, the global market is characterized by huge amounts of water. For instance, it is indicated that in order to grow a ton of cereals, 1000 tones of water are required. Basically, this is the virtual values of water contained in grains. Likewise, producing one tone of maize or rice requires 1200 tones of water. World Bank (2008) indicates that since virtual water is intrinsically inclined in the political economy, every country has a right to trade in the same. Virtual water is considered very important especially because countries can not domestically provide for all their food requirements. It is in this respect that virtual water is considered very instrumental in curbing food insecurity. Participation in international trade implies that basically, all countries export and import virtual water

However, Buchwald and Shuval (2000) point out that the segment of the population that entirely depends on agricultural production as a form of sustenance is likely to suffer. In this regard, it should be acknowledged that there is part of the population in rural areas of Palestine, Israel, Syria and Jordan that derives its livelihood from agricultural production. However, Ruttan (2002) argues that the region is experiencing a transition from an economy that is fundamentally based on quasi agriculture to an economy that is entirely based on commerce, tourism and trade. In particular, Agricultural production is Israel has been cited to comprise of an insignificant $2 \%$ of the total Gross Domestic Product. In addition, World Bank (2008) posits that the participation in Agriculture in the region is driven by strife as a result of the current political situation and lack of employment opportunities in other sectors of the economy. It is also ascertained that the level of employment in the commercial sectors of the society are increasing. Viable prospects in this respect have been experienced in the tourism sector especially as the region attained its peaceful status.

However, the countries in the Middle East are likely to experience various challenges even when utilizing the virtual water concept. In the global market, Dyson (2006) points out that these countries are always at a great disadvantage because of various reasons. To begin with, they do not have sufficient resources to effectively compete with the farmers in the north who are provided with Agricultural subsidies. This implies that the cost of production at a local scale is likely to supersede the prices provide by the international markets. Then, Yemtsove (2008) indicates that the harsh climatic conditions do not allow them to practice large scale production like their counterparts in the temperate regions. In order to practice expansive agriculture, these countries tend to mobilize significant volumes of their water for irrigation. Usually, this happens at the expense of great environmental, economic and social costs.

A classic example in this regard is exemplified by the situation in Jordan. It is indicated that Jordan imports an estimated 6 billion cubic meters of virtual water on an annual basis (Buchwald \& Shuval, 2000). 
Considering the fact that it has scarce water resources, it often imports Agricultural products that require huge quantities of water to produce such as wheat. Further, it exports services as well as products that need less water to produce as a strategy to relieve the unprecedented pressure on its water resources. Nonetheless, it still allocates close to $70 \%$ of its water to agricultural production. At this juncture, it can be noted that if Jordan reduced its water allocations and other levels of support, the result would have adverse implications on its food import strategy. In particular, food prices would possibly rise, resulting in to reduced calories for its poor population. Of great importance would be its inability to raise sufficient capital to cater for its import costs.

Another constraint that undermines the application of virtual water is the risk that increased food production is likely to compromise the political independence of the country. In this regard, Word Bank (2008) indicates that the notion of self sufficiency has always been at the core of policies of the countries this region. As such, any talks pertaining to water scarcity tend to be politically sensitive. Further, the environmental implications of adopting the virtual water strategy are massive. In particular, abandoning of the rural areas and allocating available water resources to the urban population is likely to make the countries loose their vegetation cover. Seemingly, this has negative impacts on wild life that would spill over to the tourism industry. Moreover, FAO (2008) ascertains that it would have discounting effects on the level of oxygen and carbon dioxide. In particular, it would increase the levels of carbon dioxide in the region and lead to climate change.

It is also indicated that the religious constraints prevent the holistic implementation of the concept of virtual water in the region. In this respect, Mrabet (2006) indicates that religious regulations are widely employed in charging water. The holy Quran directs that water resources should be shared with individuals who can not afford the same. In addition, religious teachings that are strictly adhered to by the population teach that people are partners with all forms of energy resources. Considering the fact that farmers in the rural areas of the Middle East are poor and entirety depended on rain fed agriculture, respective governments might find it difficult to alter the situation as it could disadvantage the farmers.

However, it should be appreciated that with the population in the region rising steadily, it is possible that food security would be affected. In addition, the probability that the increased population is likely to settle in urban areas is high. Subsequently, the demand of water in the urban areas is likely to rise because of an expected rise in the standards of living. Furthermore, Cline (2007) cites that most of the water available in the region is used for production of low value food crops at the expense of critical industrial demands and the need for production of high value food crops. Statistics also show that the municipal water in this region is often unaccounted for. It is against this background that it is argued that in order to meet the emergent needs of the rapidly growing population, there is need to reallocate the fresh water resources employed in Agricultural production to the domestic urban sector.

Notably, a viable solution does not lie in charging the rural farmers of the water they use or pushing them away from agricultural production. Rather, WHO (2008) indicates that the region needs to invest in technological advancements such as drip irrigation. These are instrumental in sustainable utilization of the available water.

\section{Future Projections}

The level of food prices in the Middle East in future is largely unknown. However, economic models ascertain that the demand of food in this region is likely to outpace the supply. Thus the current dependence of the region to imports is set to continue in to the future. This will ultimately increase the vulnerability of the region to food price shocks that are related to global production. In particular, it is projected that the dependence on grain imports will possibly increase by $63 \%$ by 2030 and further exacerbating the food deficit being experienced in Middle East (FAO, 2009). It is also posited that the increase in dairy and meat imports is also likely to increase in future. World Bank (2008) indicates that the driving force behind the increase in the net imports in the region will be increases population growth and low income.

\section{The Way forward}

The main challenge to curb food insecurity in this region should be based upon the need to increase food production and appreciate the increased reliance on food imports at the same time. In order to enhance sustainable living therefore, food production needs to be given a priority. One of the most viable approaches to this is to emulate the action that was undertaken by Brunei during the 1970s. After realizing that it is incapable of producing sufficient food for its population because of harsh climatic conditions, Brunei government purchased huge chunks of land in Australia. Food produced therein was imported to Brunei to complement local production. As a result, the country significantly reduced its dependence on foreign markets (Benson et al., 2008). As such, it became less vulnerable to the implications of fluctuations of food in the international market. Notably, part of the population in Saudi and Kuwait has assumed this trend and is scouring places in distant countries like Sudan. However, it is posited that this can easily lead to resentment by the natives who perceive the investors as intruders. 
In order to address the problem of the population growth, there would be need to increase the accessibility of the population to effective family planning services. Present statistics indicate that this region has among the highest population growth rates in the world. Failure to intervene accordingly is likely to lead to doubling of the population by 2050. This has various implications in the food security problem including increasing the need for food imports and increasing public food subsidy costs. Further, Dyson (2006) indicates that the population needs to be well educated about the importance of consuming a balanced diet. Healthy diets according to WHO (2008) are instrumental in reducing incidences of health problems such as malnutrition and non communicable diseases. This would goes a long way in cutting down the nations costs and channeling the resources to other projects geared towards social development.

In his review, Gleick (2000) indicates that there is an urgent need to diversify the economy in the region. This is based on the realization that the oil reserves are dwindling and the world is moving towards the post oil era. In addition, the decision of the International Oil Agency to invest in alternative sources of energy in a bit to curb global warming by 2050 is threatening global oil consumption. Furthermore, unemployment levels in the region are very high. This affects the level of income of the countries in the region. It is in this consideration that it is considered viable to diversify the regional economy away from oil. This will enable the locals to be able to cushion themselves against the implications of unemployment and beyond oil age era.

Furthermore, World Bank (2008) proposed the need for the region to invest in food production. In this respect, it is argued that investing in Agriculture has the capacity to diversify the economy and reduce unemployment. Then, Dyson (2006) argues that most governments are strategically working towards increasing food production. This has been influenced by the increase in the global population that has put pressure on the available resources. While it would be difficult for the region to cope without oil, Mrabet (2006) contends that it would be virtually impossible for it to survive without food.

However, it is worth acknowledging that agricultural production is limited by the harsh weather conditions. Indeed, Yemtsove (2008) indicates that the scarcity of land and water undermines extensive agricultural production. Since there is limited room for possible irrigation and/or expansion of arable land, there is an urgent need to lay greater emphasis on increasing the productivity of food with regard to yields and value of the food per unit of water and land. In order to attain this, the region is faced with the challenge of investing immensely in research, technology transfer and extension.

Another logical solution to addressing the problems of effective agricultural production is for the region to adopt the virtual water theory (Buchwald \& Shuval 2000). For instance, in the case of a country like Jordan, the Jordan valley is suitable for Agricultural production. Compared to the rest of the country, this part has warm temperatures, fertile land and a suitable environment that supports production of food crops at a low cost. In this case therefore, the respective government needs to allocate sufficient financial resources in the Agricultural sector. Further, farmers in this region can be exposed to the modern water saving strategies, equipment, planning methods and high value crop patterns. In this case, the areas are likely to continue being productive as the government gradually reallocates the remaining sources of water to the urban areas.

In addition, Cline (2007) indicates that the region needs to consider other options that when employed would improve the efficiency of irrigation, pursue intensification possibilities and enhance the overall agricultural yields in both rain fed and irrigated agricultural production. More so, the region needs to exploit production of less water intensive but high value crops such a palm trees. Notably, these have a high market value as compared to the low value food crops produced in the region. WHO (2008) asserts that the promotion of this form of production is likely to take the virtual water theory politically acceptable.

Further, is it notable that since the region is likely to remain a key player in the import market, it will possibly continue being exposed to the implications of rising prices and the risks of thin markets. Nevertheless, the levels of these risks vary considerably in line with the ability of the country to enhance domestic production and the amount of resources that the country has. It is in his consideration that it is indicated that each country needs to domesticate the risk management strategies to ensure that they are applicable to its local needs. Primary strategies in this regard include improving the efficiency of a country's supply chain in order to improve distribution and cut down costs, developing virtual stockpiles to address the quantity risk and investing heavily in infrastructure employed in production, storage and transport of food in order to reduce the exposure to incidences of cereal import volatility.

Also, it should be appreciated that water is fundamental for the food production and therefore influences food security too. Thus, the Middle East needs to adopt, implement and enforce a sustainable long term plan to address water scarcity. In addition, it needs to create viable policies that would be instrumental in not only addressing the problem of water scarcity but also changing the mindset of the youngest generation of farmers. In particular, this young generation needs to be trained and exposed to the education system that would effectively prepare them for alternative productive occupations that are readily available in the tourism, commercial, trade and industry sectors. Dyson (2006) argues that changing of the mindset should also be extended to the entire society. The academic society and the media should in this respect be employed in 
enhancing changes in attitude In particular; these bodies should oversee the implementation process and enhance political support for the theory. Increased public awareness in this regard can be achieved through campaigns, workshops and seminars that are meant to educate the public about the importance of the strategy. In order to yield optimal results, FAO (2009) indicates that this plan needs to be self initiated, well financed and well planned in to different phases that can be implemented with ease.

More over, it would be imperative to ensure that the virtual waters are traded in a secure and just manner. This is critical in elimination of possible political conflicts in the region that are likely to stem from control of water resources and food prices. Thus the United Nations should endorse this virtual water theory and accord it a resolution status. This according to studies will enhance the credibility of the resolution and enhance accurate, effective and fair virtual water trade between global nations. Of great importance is the fact that it would overcome probable political conflicts and security concerns in the Middle East.

Furthermore, Cline (2007) proposes that the Middle East should liaise with the donor community to form a World Water Fund. This would be instrumental in assisting the poor nations that are found in the region. In this regard, it is worth noting that some countries like Palestine and Egypt are still in their transition phase and can not generate sufficient foreign currency to make food purchases that would effectively address their dietary needs at the current market prices. In addition, these countries have limited resources that do not allow them to benefit from the virtual water trade. Thus such a fund would go a long way in enabling such nations to have access to sufficient and basic food supplies.

In order to deal with the implications of climate change, various strategies can be adopted. To begin with, the governments in the Middle East need to take timely measures and improve the disaster risk management of the population. In this regard, the vulnerable population needs to be informed about its status in advance. Then, the communities need to be empowered accordingly to deal with the emergent risks. This requires partnerships and collaborations between major stakeholders. Most importantly, the strategies should be mainstreamed within the government plans and gaps between different sectors bridged accordingly.

Further, Cline (2007) indicates that respective governments need to strengthen the community based developments. This would be instrumental in enhancing the coping capacity of such populations and enabling them to rebuild their lives after a disaster. In addition, the governments need to ensure that all the communal structures are resilient to the effects of climate change. Of great importance however is to provide viable resources that would cushion the population against the after effects of climate change.

\section{Conclusion}

From the analysis, it is certain that food security in the Middle East is compounded by various complexities. This situation is contributed to by various factors that include climate change, population growth and most importantly, water scarcity. Coupled with lack of political will to invest in agriculture, these factors have greatly undermined agricultural production in the region. It is also clear that the complexities differ considerably between the countries found therein. This is influenced by the individual economic wellbeing of these countries. Seemingly, countries with a high level of income face minimal changes as they can easily buy food and subsidize the costs to make it affordable. Notably, the region relies heavily on food imports for its consumption. In particular, it imports cereals more than other food products. However, dairy and meat products are also being increasingly imported because of urbanization ad diversification of the population.

It can be ascertained that the challenges that the region is facing have far reaching implications on the wellbeing of its population. Engagement in virtual water trade has been proposed as the most viable approach of addressing the implications of water scarcity. However, the approach is faced with various challenges that range from social and cultural to economic and religious. These challenges need to be addressed before implementation of the virtual water theory. Alternatively, the region can embark on diversification of its economy to increase employment opportunities and raise the levels of income, control of its population growth by availing effective family planning services to the population and increasing the level of public awareness through education, public campaigns and workshops in order to change the mindset of the entire population. Notably, these would be instrumental in addressing food security in the region.

\section{References}

Benson, T., Minot, J., Pender, M., \& Robles, J. (2008). Global Food Crisis. USA: IFPRI.

Buchwald, S., \& Shuval, H. (2000). Virtual Water Theory. Unpublished.

Cline, W. (2007). Agriculture and Global Warming. USA: Peterson Institute.

Dorosh P. (2008). Food Prices in Middle East. USA: World Bank.

Dyson, T. (2006). Population and Food. UK: Rutledge.

Food and Agriculture Organization. (2008). Food Insecurity in MENA. Rome: FAO.

Food and Agriculture Organization. (2009). Feeding the World by 2030. Rome: FAO.

Gleick, H. (2000). Global Water Resources. Oxford: University Press. 
Mrabet, R. (2006). Food Production and Efficient Water Use in ASALS. Experimental Agriculture, 37: $237-49$. Najj, T. (1995). Water and Middle East. UK: MIT.

Ruttan, V. (2002). Productivity in Agriculture. Journal of Economic Perspective, 16 (3): 162-86.

World Health Organization. (2008). Implications of Climate Change. WHO.

World Bank. (2008). Food Security in MENA. USA: World Bank.

Yemtsove, R. (2008). Addressing Food Crisis. USA: Word Bank. 
The IISTE is a pioneer in the Open-Access hosting service and academic event management. The aim of the firm is Accelerating Global Knowledge Sharing.

More information about the firm can be found on the homepage:

http://www.iiste.org

\section{CALL FOR JOURNAL PAPERS}

There are more than 30 peer-reviewed academic journals hosted under the hosting platform.

Prospective authors of journals can find the submission instruction on the following page: http://www.iiste.org/journals/ All the journals articles are available online to the readers all over the world without financial, legal, or technical barriers other than those inseparable from gaining access to the internet itself. Paper version of the journals is also available upon request of readers and authors.

\section{MORE RESOURCES}

Book publication information: http://www.iiste.org/book/

Academic conference: http://www.iiste.org/conference/upcoming-conferences-call-for-paper/

\section{IISTE Knowledge Sharing Partners}

EBSCO, Index Copernicus, Ulrich's Periodicals Directory, JournalTOCS, PKP Open Archives Harvester, Bielefeld Academic Search Engine, Elektronische Zeitschriftenbibliothek EZB, Open J-Gate, OCLC WorldCat, Universe Digtial Library, NewJour, Google Scholar

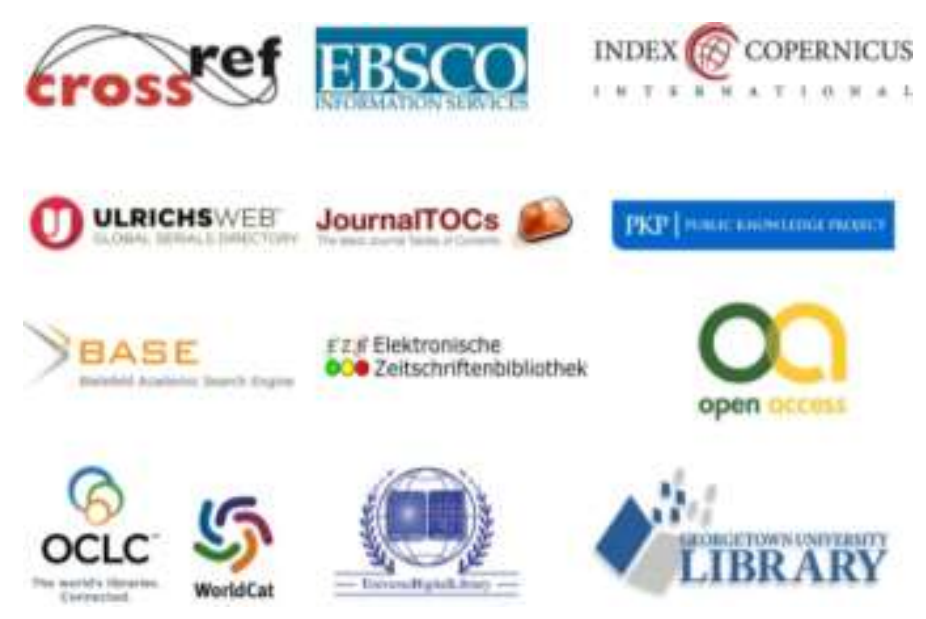

